\title{
Patterns of Associations Between Maternal Symptoms and Child Problem Behaviors: The Mediating Role of Mentalization, Negative Intentionality, and Unsupportive Emotion Socialization
}

\author{
${\text { Gizem } \text { Arikan }^{1} \text { (D) Asiye Kumru }}^{1}$
}

Published online: 27 August 2020

(c) Springer Science+Business Media, LLC, part of Springer Nature 2020

\begin{abstract}
We examined how maternal depression, anxiety, hostility, mentalization, negative intentionality (NI), and unsupportive emotion socialization (UES) predict child internalizing and externalizing problem behaviors (CIEPB). Mothers $(N=537)$ of toddlers $\left(M_{\text {age }}=23.26\right.$ months, Range 10-44 months) completed the Brief Symptom Inventory, the Parental Reflective Functioning Questionnaire, the Infant Intentionality Questionnaire, the Coping with Children's Negative Emotions Scale, and the Child Behavior Checklist. All maternal symptoms negatively predicted mentalization and positively predicted NI, UES, and CIEPB. NI and UES mediated the relationship between maternal symptoms and CIEPB. Negative intentionality mediated the link between maternal hostility and internalizing behaviors, indicating a possible intervention area. Mentalization had an effect on externalizing behaviors only for high-SES, anxious mothers, underscoring the role of SES. Thus, the relationship between maternal symptoms, cognitive and behavioral parenting characteristics and CIEPB supports the multifinality principle for early childhood psychopathology development and shows the importance of screening for maternal symptoms and CIEPB.
\end{abstract}

Keywords Maternal symptoms · Mentalization · Negative intentionality $\cdot$ Unsupportive emotion socialization $\cdot$ Child problem behaviors

Early childhood problem behaviors are known to be the first indicators of adjustment issues [1,2], which are leading factors in the development of various psychological problems such as depression [3], substance abuse, and anxiety [4]. Two categories of problem behaviors have been extensively explored-namely, internalizing and externalizing behaviors [5]. Externalizing behaviors involve aggressive behaviors and hyperactivity in children, triggered by anger, fear, and frustration, whereas internalizing behaviors typically indicate anxiety and depression in the form of social withdrawal and fearfulness [5]. These problem behaviors become detectable from as early as 12 months $[6,7]$ and are likely

Gizem Arikan

gizem.arikan@ozyegin.edu.tr

Asiye Kumru

asiye.kumru@ozyegin.edu.tr

1 Department of Psychology, Ozyegin University, Nisantepe Mah. Orman Sok. Cekmekoy, Istanbul, Turkey to persist from early childhood [8] into adolescence [9] and adulthood [10].

A wide array of environmental factors and parental characteristics, such as personality [11] and parenting behaviors can contribute to the complexity of child development [12] and the occurrence of problem behaviors. Individual differences in parental psychopathology, cognitions about parenting, and emotion socialization are highly salient factors in child development. In the relevant literature, parental psychopathology, cognitions, and socializing behaviors are listed as critical etiological factors with unique as well as joint contributions to problem behaviors in young children [13]. For example, maternal depressive symptomatology [14] and maternal anxiety [15] have been associated with both externalization and internalization problems in children [16-18]. Since psychopathology is also linked with negative cognitions about the self, the world, and the future [19], it can also contribute to negative cognitions and attributions towards children [20] as well as negative maternal parenting behaviors and unsupportive emotion socialization [21]. However, there is a lack of research focusing on how 
different maternal symptoms impact mothers' cognitive and attributional styles, emotion socialization, and child problem behaviors. Therefore, the present study aims to examine how different maternal symptoms are associated with other maternal cognitive and behavioral factors in predicting toddlers' externalizing and internalizing behaviors.

\section{Maternal Symptoms}

Over the decades, research has consistently indicated transgenerational transmission of psychopathology [22, 23], especially maternal psychopathology [16, 24]. For example, longitudinal studies have demonstrated that children with parents who suffer from psychiatric disorders are more likely to develop various childhood and adulthood disorders than children with nonsymptomatic parents [25, 26]. Although maternal and childhood mental health predominantly focuses on maternal depression and its effects, mothers do experience other psychological disorders while raising their children (i.e., anxiety, (16); borderline and antisocial symptoms, (27)). Further, some features of psychopathology, like hostility-which can reflect certain adulthood disorders (i.e., antisocial personality disorder, depression, borderline personality disorder, (28)) — are positively related to child internalizing and externalizing problems [29]. Therefore, in addition to commonly reported maternal psychological symptoms of depression and anxiety in the early years of child development [30], it is also important to explore whether maternal hostility contributes to externalizing and internalizing problem behaviors during toddlerhood based on the transmission model [22]. In this regard, whether a specific maternal psychological symptom predicts a specific child psychopathology (equifinality) or multiple childhood psychological problems (multifinality) is open to debate [31]. Thus, examining the presence of different symptoms in mothers [32] can extend our understanding of the mechanism underlying the subsequent development of psychopathology in children.

\section{Maternal Cognitive Aspects: Maternal Mentalization and Negative Intentionality}

Besides psychological symptoms, facets of maternal cognitive processes-including mentalization and negative intentionality-may influence childhood problem behaviors. Mentalization, a concept that emerged from the psychoanalytic tradition and lessons learned from a wide number of psychodynamic cases [33], can be defined as a parent's capacity to identify and understand the sources of a child's behavior, anticipate associated emotions, mental states, and conduct, and adjust his/her own behaviors in light of the child's needs [34-36]. Previously, mindmindedness [37, 38], accepting the child as an individual with a mind, was an important construct related to attachment [39]. Although mind-mindedness can be evaluated as a facet of mentalization, there are some differences between these two constructs. While mind-mindedness is more centered on understanding the mindset of the child and how this can enable the development of a theory of mind in children [38], mentalization also focuses on feelings, making predictions about a child's emotions and behaviors, being open to the child's experiential world and actively reading his/her wishes. In fact, mentalization, as derived from psychodynamic psychotherapy, proposes a more comprehensive understanding of a child, which allows forming links with emotion socialization [40] and providing a better framework to reflect on the sources of parenting behaviors.

Studies have shown that lower mentalization capacity in Dutch mothers to be positively associated with maternal insensitivity [41] and an increase in physical aggression in infants aged 6 to 12 months [42]. Thus, maternal mentalization can be a critical factor shaping child aggression in later years. Yet, there is a lack of research examining how maternal mentalization is explicitly related to child internalizing and externalizing behaviors during toddlerhood.

In addition to maternal mentalization, mothers can also influence their children's problem behaviors through ascribing negative attributions to their actions and appeals. Although the vast majority of mothers love and care for their children, having a toddler can evoke adverse experiences in mothers [43], which may reveal unconscious negative intentionality [44]. Negative intentionality can be defined as a maternal presumption that a child's negative behavior is intentional (i.e., my infant cries to annoy me) that triggers insensitive handling of the child [45] and the use of physical punishment in response [46]. Negative intentionality is a synonym for hostile attributions, a concept that originally derives from social cognitive learning theory [47]. According to Bandura [47], parental displays of hostile attribution toward certain behaviors often result in children adopting the same interpersonal strategies as their parents and exhibiting more externalizing problems [48].

A study with 9 to 12-year-old children [49] demonstrated that parents' negative attributions about child intentionality were associated with negative child behaviors and problems. Further, maternal attributions can contribute to conduct disorder by age three [50] and later in kindergarten [51]. Although there is a limited number of studies on negative intentionality and child internalizing behaviors, a study with Turkish toddlers showed that negative maternal intentionality seems to play a critical role in children's internalizing behaviors regardless of parenting stress and SES levels [52]. However, neither of these studies examined whether 
maternal intentionality varies with respect to different maternal symptoms vis-à-vis child problem behaviors.

\section{Unsupportive Emotion Socialization}

Like maternal symptoms and cognitive aspects, mothers' maladaptive parenting behaviors can also affect child internalizing and externalizing problems. Especially in toddlerhood, both the child's development and demand for autonomy [53] trigger new parenting tasks (i.e., limit setting, support in coping with negative emotions) and underscore the need for appropriate parental emotion socialization strategies [54]. Poor parenting behaviors, such as negative and unsupportive reactions to children's behavior, can exacerbate internalizing and externalizing behavior patterns [55]. For example, if a mother lacks the capacity to adopt supportive strategies to help regulate her child's negative emotions [56], the child may suffer from his/her own dysregulated emotions [57], further increasing the likelihood of future problem behaviors $[1,58]$. Therefore, it is important to examine how unsupportive parental socialization behaviors toward a child's negative emotions can impact his/her problem behaviors during toddlerhood.

\section{The Mediating Role of Maternal Cognitive Aspects and Unsupportive Emotion Socialization in the Relationship Between Maternal Symptoms and Child Problem Behaviors}

Maternal symptoms can also impair maternal cognitions and parenting behaviors, which, in turn, may affect child problem behaviors. To examine the interactive role of maternal factors in child problem behaviors, researchers have offered a developmental transmission of psychopathology model showing how depressed mothers' maladaptive cognitions and parenting behaviors can boost the risk of childhood and adolescent psychopathology [59]. There is empirical support showing that maternal symptoms influence not only child problem behaviors [25], but also maternal cognitions $[45,60]$ and parents' emotion socialization $[61,62]$. For instance, one study demonstrated that mothers with anxiety disorder did not only report more negative cognitions (i.e., negative expectations and appraisals) but also exhibited more intrusive behavior during their interactions with their children than mothers without this disorder [63]. Also children with anxiety disorder had mothers, who used less positive emotion verbal expression, and were less likely to engage in emotion discussions [64]. Further, maternal cognitions and attitudes, together with maternal symptoms, seem to affect child outcomes [65], and negative or maladaptive attributions mediate the association between maternal symptoms and parent-child interaction [66].

Moreover, studies have shown that maternal psychopathology and unsupportive emotion socialization are related $[55,67,68]$. Empirical findings reveal that mothers with maladaptive psychopathology seem to drift away from optimal emotion socialization strategies-namely, being attentive and supportive when the child needs to express emotions, and facilitating his/her emotions appropriately [69] — adversely impacting the child's behavioral problems [70]. Unsupportive emotion socialization strategies, such as distressing and/or punitive reactions, are associated with emotion dysregulation and symptomatology in children [71]. Furthermore, based on existing models [31, 59], parenting behaviors (i.e., unsupportive emotion socialization) might mediate the relationship between maternal psychopathology and child outcomes. However, none of these studies examined specifically how maternal mentalization and ascribing negative attributions to a child's intentions, as well as maternal emotion socialization, mediate the relationships between different types of maternal symptoms and problem behaviors in toddlers.

\section{The Mediating Role of Unsupportive Emotion Socialization in the Relationship Between Maternal Cognitive Aspects and Child Problem Behaviors}

It is also possible that maternal socialization behavior vis-à-vis a child's negative emotions can be influenced by maternal cognitions-namely, mentalization and ascribing negative attributions to the child's intentions. According to the Heuristic Model of the Socialization of Emotion [69], among parental characteristics, certain cognitivebased factors (i.e., emotion-related beliefs) are associated with emotion-related parenting practices (i.e., reactions to a child's emotions that, in turn, produce adverse outcomes in the child). Indeed, studies reveal that a lack of parental mentalization is related to insensitive and harsh parenting [72] and engaging in unhelpful discipline methods [33]. Also, maladaptive maternal cognitions, such as negative perceptions about the locus of control, negatively influenced parenting discipline strategies [65] that could be linked to a child's problem behaviors [73]. Yet, there is no research examining how facets of maternal cognition and unsupportive emotion socialization affect child problem behaviors and play a mediating role between maternal symptoms and child problem behaviors. 


\section{The Present Study}

Proceeding from models $[31,59]$, the first aim of the study is to understand whether maternal symptoms of depression, anxiety, and hostility differentially predict child internalizing and externalizing behaviors as well as parental cognition and emotion socialization behavior. The second aim is to examine whether maternal cognitive aspects and unsupportive emotion socialization mediate the relationship between maternal symptoms and child problem behaviors. We hypothesized that maternal symptoms of depression, anxiety, and hostility would negatively predict parental mentalization and positively predict negative intentionality, unsupportive emotion socialization, and child internalizing and externalizing behaviors. Unsupportive emotion socialization and child internalizing and externalizing behaviors would be predicted negatively by mentalization and positively by negative intentionality. Finally, we hypothesized that negative maternal emotion socialization would negatively predict child internalizing and externalizing behaviors. Given that there is almost no literature, the present study aimed to explore two key aspects of mediating relations. The first is the mediating role of maternal mentalization, negative intentionality and emotion socialization in the associations of maternal symptoms with child problem behaviors; the second is the mediating role of negative emotion socialization in the relationships of maternal mentalization and negative intentionality with child internalizing and externalizing behaviors.

\section{Method}

\section{Participants}

The study sample consisted of 537 mothers $(M=32.03$, $S D=4.75$, Range 18-47 months) and their children (48\% Female, $M=3.26$ months, $S D=7.47$, Range 10-44 months) who were recruited via advertisements in preschools, daycares, and community/family-health centers. The inclusion criteria were being the biological mother of a toddler and the absence of any medical conditions (for both mothers and children). Ninety-six percent of the mothers were married, and $49 \%$ were employed. In terms of mothers' education, $2 \%$ of participants had not completed primary school, and the educational attainment of the remaining participants was as follows: completed elementary school (11\%), secondary school (13\%), high school (23\%), 2-year-college (9\%), university (31\%), and graduate school (11\%). During data collection, the monthly minimum wage in Turkey was $1647 \mathrm{TL}$, approximately $\$ 549$ [50]. Seventeen percent of mothers reported monthly income below $1500 \mathrm{TL}, 26 \%$ from 1501 to $3000 \mathrm{TL}, 16 \%$ from 3001 to $5000 \mathrm{TL}$, the poverty line for a 4-member household at the time of data collection [74], $18 \%$ from 5001 to $7500 \mathrm{TL}$, and $23 \% 7501 \mathrm{TL}$ or more. These scales were coded on a five-point scale from 1 (below 1500TL) through to 5 (7501TL or more).

\section{Procedure}

The ethics board of a university in Turkey approved the study, and the data was collected during home visits by undergraduate and graduate students. After giving informed consent, mothers completed the counterbalanced questionnaire packs, which took approximately $45 \mathrm{~min}$. A baby diaper or a toy package, and a children's activities booklet were offered as appreciation to participating mothers.

\section{Measures}

\section{Demographic Form}

Mothers completed questions about marital status, education level, household income, occupational status, parental age, and children's age and sex.

\section{Maternal Symptoms}

The Brief Symptom Inventory [75] comprises 53-items on physiological and psychological complaints over the past seven days, using a 5-point Likert scale $(0=$ not at all; $4=$ extremely). The Turkish adaptation [76] found Cronbach's alpha values of. 88 for depression, 0.87 for anxiety, and 0.76 for hostility. The respective values in the present study were 0.90 for depression, 0.90 for anxiety, and 0.80 for hostility.

\section{Maternal Mentalization}

The Parental Reflective Functioning Questionnaire-1 (PRFQ-1; [77]) was used to measure maternal mentalization. It has 39 items assessing parents' capacity to mentalize and accept a child's uniqueness via an 8-point Likert scale $(0=$ strongly disagree, $7=$ strongly agree $)$ that yields three subscales, namely, interest and curiosity in the child's mental states (High-Low Scale), certainty about these mental states (Middle Scale), and pre-mentalization, non-mentalization, and malevolent attributions (Low-High Scale). In the Turkish version [78], Cronbach's alpha values were 0.75 for the High-Low Scale, 0.86 for the Middle Scale, and 0.76 for the Low-High Scale [54]. In our study, the 
respective Cronbach's alpha values were $0.75,0.86$, and 0.86 , and the mean score of all subscales was used for maternal mentalization.

\section{Negative Intentionality}

The mother's perception of child intentionality was assessed with the 21-item Infant Intentionality Questionnaire (IIQ; $[45,79])$, indicating positive and negative parental attributions ascribed to child behaviors in a 5 -point Likert scale $(1=$ never $; 5=$ always $)$. The negative intentionality subscale (i.e., "Does your baby do things on purpose to be annoying?") was previously used in other studies, and the Cronbach's alpha values were $0.81[80,81]$ and 0.82 [52]. In the present study, the value of Cronbach's alpha was 0.82 .

\section{Unsupportive Emotion Socialization}

Coping with Children's Negative Emotions Scale (CCNES; [67]) consists of 12 scenarios and a 7-point Likert scale $(1=$ very unlikely, $7=$ very likely $)$ corresponding to supportive emotion socialization behaviors and unsupportive emotion socialization behaviors. For our study, we used only unsupportive emotion socialization subscales. The Turkish adaptation and psychometric properties of the scale were tested previously [81], and the Cronbach's alpha values ranged from 0.74 to 0.86 . In the present study, unsupportive emotion socialization, including subscales of minimization, punitive, and distress reactions had Cronbach's alpha values of $0.85,0.86$, and 0.83 , respectively.

\section{Internalizing and Externalizing Behaviors}

Child problem behaviors were assessed via the Child Behavior Checklist: Ages 18-60 Months (CBCL 04-18; [5, 82]) consisting of 113 questions, and 100 of them responded on a 3 -point Likert scale $(0=$ not true, $2=$ very true or often true $)$. The checklist was adapted to Turkish [83] and had good psychometric properties. In our study, Cronbach's alpha values of the internalizing and externalizing behaviors subscales were 0.84 and 0.88 , respectively.

\section{Data Analytic Approach}

The Statistical Package for Social Sciences version 20 [84] and Mplus version 8 [85] were used for the analysis. Before examining the hypothesized path model, univariate (Z-Score $>3.29$ ) and multi-varied outliers (Mahalanobis distance $p<0.001$ ) were identified [86]. Where only a single missing data point was missing, the grand mean of the scale was used to substitute the missing score point.

For the path models, Chi-Square results were checked for the significance of the path models, and goodness-of-fit indices below were used to indicate a good model fit. For root mean square error of approximation (RMSEA), values smaller than or equal to $0.05[87,88]$ for the standardized root mean square residual (SRMR), values of.05 or less indicate adequate fit [89] and for comparative fit index (CFI) values equal to or higher than 0.90 [90] were used. A bootstrap procedure (1000 RESAMPLES) with a $95 \%$ bias-corrected confidence interval (CI) was adhered to, and $p<0.05$ effect was considered as significant [91].

\section{Results}

\section{Data Preparation}

The univariate outlier cases were replaced with a raw score of one unit larger or smaller than the next highest/lowest score in the scale [85]. There was no multivariate outlier. All maternal symptoms were positively correlated with each other (ranging from 0.61 to 0.85 ). Maternal education and household income were correlated $(r=0.82, p<0.01)$ and the summed $z$-scores were used to indicate SES. The variables in the path models were correlated with child internalizing and externalizing behaviors (see Table 1).

\section{Path Analysis}

In the path analysis (See Fig. 1), SES was negatively correlated with all maternal symptoms, unsupportive emotion socialization, and child internalization and externalization behaviors and positively correlated with mentalization. Therefore, it was assigned as a control variable in all maternal symptom path models. Also, since child age was negatively related to both negative intentionality and externalizing behaviors and child sex was related only to externalizing behaviors, age was controlled for negative intentionality and externalizing behaviors and sex was controlled for externalizing behaviors in all maternal symptom models. We ran three separate path models for the maternal symptoms of depression, anxiety, and hostility (see Table 2). In all maternal symptom models, the child's age positively predicted negative intentionality $(\beta=0.15, p<0.01$ in each model). SES positively predicted maternal mentalization $(\beta=0.28, p<0.001$ in the depression and hostility models; and $\beta=0.27, p<0.001$ in the anxiety model), and was negatively associated with unsupportive emotion socialization $(\beta=-0.33, p<0.001$ in the depression model; $\beta=-0.35, p<0.001$ in the anxiety model; and $\beta=-0.34, p<0.001$ in the hostility model), maternal depression $(\beta=-0.23, p<0.001$ in the anxiety model; $\beta=-0.17, p<0.001$ in the hostility model; $\beta=-0.18, p<0.001$ in the depression model), child internalizing $(\beta=-0.18, p<0.001$ in the depression model; 


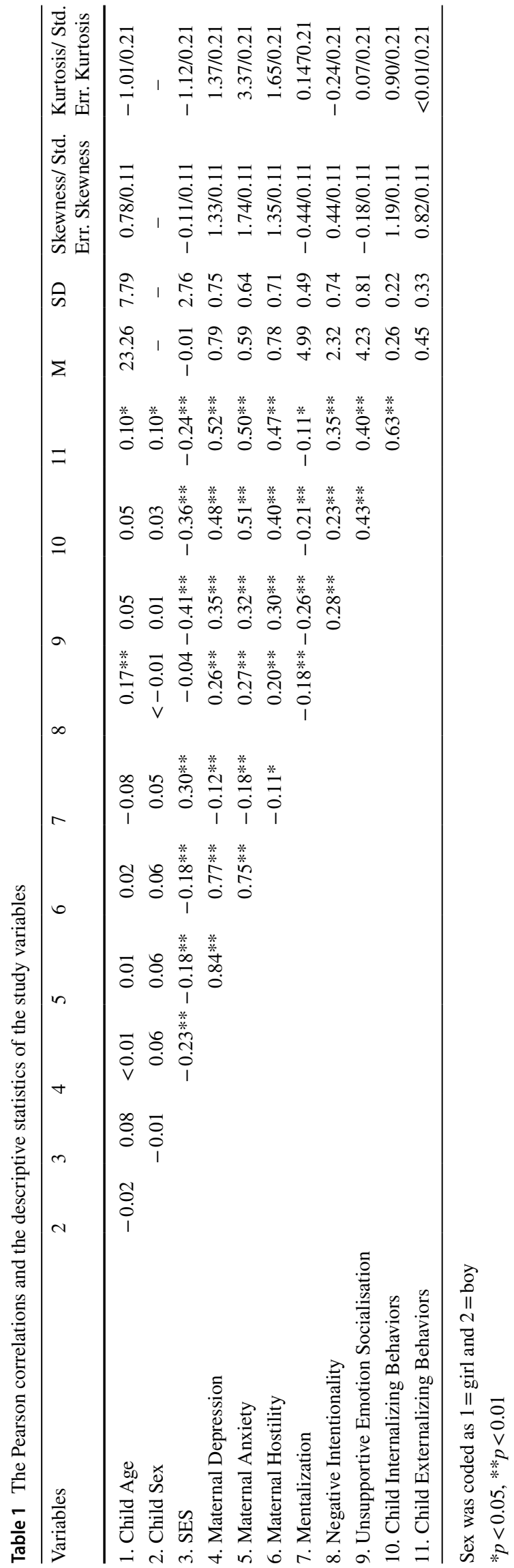

and $\beta=-0.20, p<0.001$ in the anxiety and hostility models) and externalizing behaviors $(\beta=-0.12, p<0.01$ in the depression model; $\beta=-0.15, p<0.001$ in the anxiety model; and $\beta=-0.14, p<0.001$ in the hostility model). Sex positively predicted externalizing behaviors $(\beta=0.07$, $p<0.05$ in all the models). Age positively predicted negative intentionality ( $\beta=0.15, p<0.01$ in all models) but not externalizing behaviors.

In the path Model 1 (Depression), the contributions of the variables to the model were as follows: $5 \%$ for maternal depression, $9 \%$ for negative intentionality $9 \%$ for mentalization, and $29 \%$ for unsupportive emotion socialization (See Fig. 1 for standardized coefficients). Maternal depression predicted negative intentionality, unsupportive emotion socialization, child internalizing and externalizing symptoms but not maternal mentalization. Maternal mentalization negatively predicted unsupportive emotion socialization, and negative intentionality intention attribution predicted it positively. Negative intentionality predicted unsupportive emotion socialization and child internalization but not externalizing behavior. Unsupportive emotion socialization positively predicted both problem behaviors. The indirect effects in Model 1 are presented in Table 3. Negative intentionality mediated the relationship between depression and externalizing behaviors but not internalizing behaviors. Unsupportive emotion socialization mediated the associations of depression with internalizing and externalizing behaviors and the links of SES with both problem behaviors. There was no mediating role for unsupportive emotion socialization in the links between maternal mentalization and negative intentionality and both problem behaviors.

In the path Model 2 (Anxiety), the contribution of maternal anxiety to the model was $3 \%$, mentalization was $10 \%$, negative intentionality was $10 \%$, and unsupportive emotion socialization was $28 \%$ (See Fig. 1 for standardized coefficients). Maternal anxiety predicted mentalization negatively and negative intentionality positively, as well as unsupportive emotion socialization and child internalizing and externalizing symptoms but not maternal mentalization. Maternal mentalization negatively predicted externalizing but not internalizing behaviors and unsupportive emotion socialization. Negative intentionality predicted unsupportive emotion socialization and child internalization but not externalizing. Unsupportive emotion socialization positively predicted both problem behaviors. For the indirect effects (see Table 3), negative intentionality played a mediating role between maternal anxiety and externalizing behaviors but not internalizing ones. Unsupportive emotion socialization mediated the relationships between maternal anxiety and internalizing and externalizing behaviors. Further, the association between SES and externalizing behaviors was mediated by maternal anxiety, maternal mentalization, negative intentionality, and negative emotion socialization. 


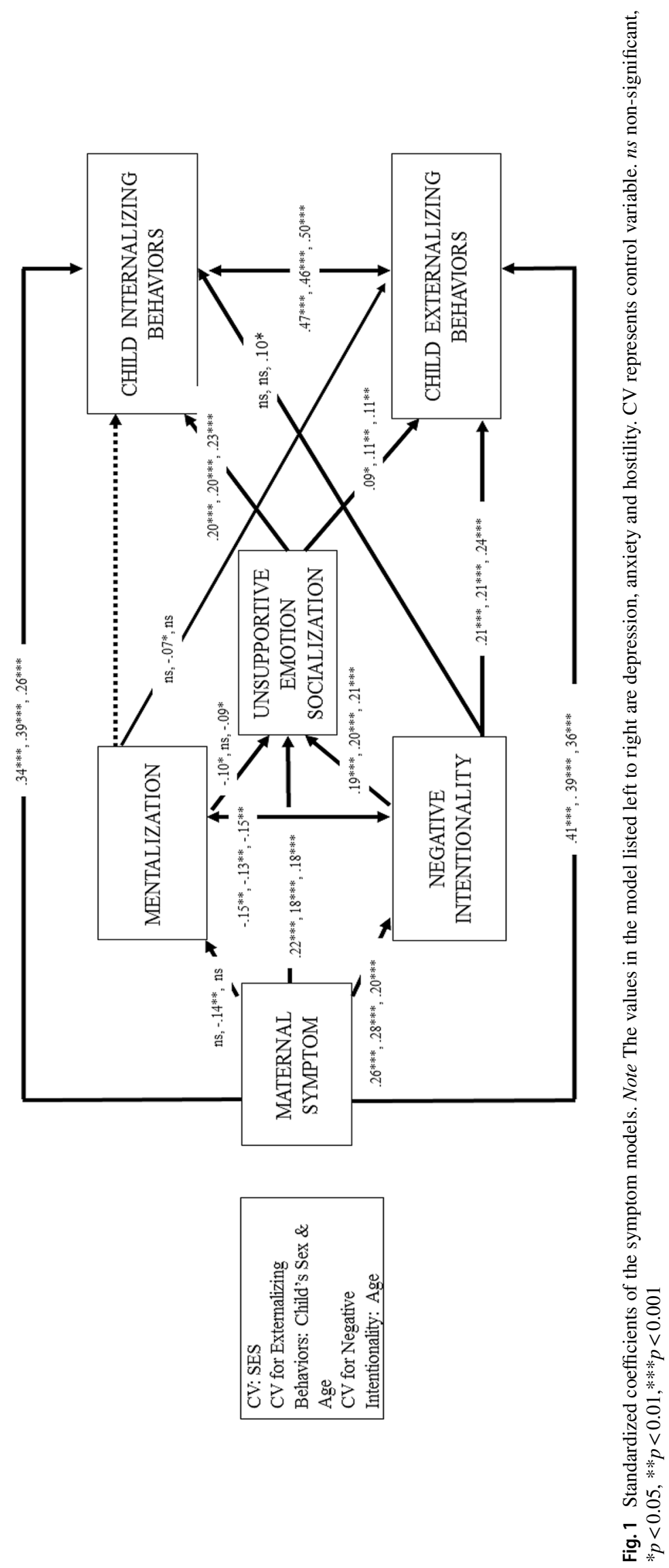


Table 2 Model fit indices of the path models

\begin{tabular}{llllllll}
\hline Model & CFI & SRMR & RMSEA & 90\% CI for RMSEA & $\chi^{2}$ & $d f$ & $p$ \\
\hline Model 1 (Depression) & 0.996 & 0.025 & 0.026 & $0.000-0.059$ & 12.347 & 9 & 0.194 \\
Model 2 (Anxiety) & 0.996 & 0.025 & 0.028 & $0.000-0.060$ & 12.916 & $\mathrm{~s}$ & 0.166 \\
Model 3 (Hostility) & 0.996 & 0.025 & 0.025 & $0.000-0.058$ & 12.109 & 9 & 0.207 \\
\hline
\end{tabular}

Table 3 Indirect effects in the models with different maternal symptoms

\begin{tabular}{|c|c|c|c|c|c|c|}
\hline \multirow[t]{2}{*}{ Relationship } & \multirow[t]{2}{*}{ Mediators } & \multicolumn{3}{|c|}{ Coefficients } & \multicolumn{2}{|c|}{$\begin{array}{l}1000 \text { Bootstrapping } \\
\text { Bias-Corrected } 95 \% \mathrm{CI}\end{array}$} \\
\hline & & Estimate & SE & $\mathrm{p}$ & Lower limit & Upper limit \\
\hline \multicolumn{7}{|l|}{ Model 1 (depression) } \\
\hline SES to child internalizing behaviors & Unsupportive emotion socialization & -0.005 & 0.002 & $<0.001$ & -0.008 & -0.003 \\
\hline SES to child externalizing behaviors & Unsupportive emotion socialization & -0.004 & 0.002 & $<0.05$ & -0.006 & -0.001 \\
\hline SES to child internalizing behaviors & Maternal depression & -0.006 & 0.002 & $<0.001$ & -0.009 & -0.004 \\
\hline SES to child externalizing behaviors & Maternal depression & -0.011 & 0.002 & $<0.05$ & -0.015 & -0.007 \\
\hline $\begin{array}{l}\text { Maternal depression to child internalizing behav- } \\
\text { iors }\end{array}$ & Unsupportive emotion socialization & 0.013 & 0.004 & $<0.01$ & 0.006 & 0.020 \\
\hline $\begin{array}{l}\text { Maternal depression to child externalizing } \\
\text { behaviors }\end{array}$ & Unsupportive emotion socialization & 0.009 & 0.004 & $<0.05$ & 0.015 & 0.035 \\
\hline $\begin{array}{l}\text { Maternal depression to child externalizing } \\
\text { behaviors }\end{array}$ & Negative Intentionality & 0.024 & 0.006 & $<0.001$ & 0.001 & 0.012 \\
\hline \multicolumn{7}{|l|}{ Model 2 (Anxiety) } \\
\hline SES to child internalizing behaviors & Unsupportive emotion socialization & -0.006 & 0.002 & $<0.001$ & -0.009 & -0.003 \\
\hline SES to child externalizing behaviors & Unsupportive emotion socialization & -0.005 & 0.002 & $<0.05$ & -0.008 & -0.002 \\
\hline SES to child externalizing behaviors & Maternal anxiety & -0.008 & 0.002 & $<0.001$ & -0.012 & -0.005 \\
\hline Maternal anxiety to child internalizing behaviors & Unsupportive emotion socialization & 0.013 & 0.004 & $<0.01$ & 0.007 & 0.020 \\
\hline Maternal anxiety to child externalizing behaviors & Unsupportive emotion socialization & 0.011 & 0.005 & $<0.05$ & 0.004 & 0.020 \\
\hline M anxiety to child externalizing behaviors & Unsupportive intentionality & 0.030 & 0.008 & $<0.001$ & 0.019 & 0.044 \\
\hline SES to child externalizing behaviors & Mentalization & 0.002 & 0.001 & 0.06 & 0.000 & 0.004 \\
\hline \multicolumn{7}{|l|}{ Model 3 (Hostility) } \\
\hline SES to child internalizing behaviors & Unsupportive emotion socialization & -0.006 & 0.002 & $<0.001$ & -0.009 & -0.004 \\
\hline SES to child externalizing behaviors & Unsupportive emotion socialization & -0.005 & 0.002 & $<0.05$ & -0.008 & -0.002 \\
\hline SES to child externalising behaviors & Maternal hostility & -0.008 & 0.002 & $<0.001$ & -0.012 & -0.005 \\
\hline SES to child internalising behaviors & Maternal hostility & -0.004 & 0.001 & $<0.01$ & -0.006 & -0.002 \\
\hline Maternal hostility to child internalizing behaviors & Unsupportive emotion socialization & 0.013 & 0.004 & $<0.01$ & 0.007 & 0.021 \\
\hline Maternal hostility to child externalizing behaviors & Unsupportive emotion socialization & 0.010 & 0.004 & $<0.05$ & 0.004 & 0.018 \\
\hline Maternal hostility to child internalizing behaviors & Negative intentionality & 0.006 & 0.003 & $<0.05$ & 0.002 & 0.012 \\
\hline Maternal hostility to child externalizing behaviors & Negative intentionality & 0.022 & 0.006 & $<0.001$ & 0.013 & 0.035 \\
\hline
\end{tabular}

In the path Model 3 (Hostility), hostility (3\%), mentalization (9\%), negative intentionality $(6 \%)$, and unsupportive emotion socialization $(30 \%)$ contributed to the model (See Fig. 1 for standardized coefficients). Maternal hostility predicted negative intentionality, unsupportive emotion socialization, child internalizing and externalizing symptoms but not maternal mentalization. Maternal mentalization predicted unsupportive emotion socialization negatively, and negative intentionality predicted it positively. Negative intentionality predicted unsupportive emotion socialization and both child problem behaviors. Unsupportive emotion socialization positively predicted both problem behaviors. For indirect effects see, see Table 3. Negative intentionality mediated the relationship between hostility and externalizing behaviors, but not internalizing ones. Unsupportive emotion socialization mediated the links between hostility and internalizing and externalizing behaviors. The associations of SES with internalizing and externalizing behaviors were mediated by hostility and unsupportive emotion socialization. However, there were no mediating roles for mentalization in the relations of hostility with child problem behaviors or for unsupportive emotion socialization in the relations of 
mentalization and negative intentionality with child problem behaviors.

\section{Discussion}

The path models for maternal depression, anxiety and hostility indicated that patterns of associations for toddlers' problem behaviors do vary. Below we discuss how internalizing and externalizing behaviors are predicted by maternal symptoms, cognitive aspects and unsupportive emotion socialization and detail the indirect role of cognitive aspects and unsupportive emotion socialization on child problem behaviors.

\section{Maternal Symptoms}

All maternal symptoms were highly correlated with each other indicating possible comorbidity [92-94]. Thus, as Ader [95] suggested statistical models should first consider theory and existing theoretical models. As expected, maternal depression, anxiety, and hostility positively predicted internalizing and externalizing behaviors, which provided support for the "multifinality" principle rather than that of "equifinality" [30]. That is, there is no one-to-one relationship between maternal symptoms and child problem behaviors. Instead, there is quite a complicated relationship, such that any kind of maternal symptom seems to be a candidate that promotes different types of problems in children even during toddlerhood. Consistent with previous research on the transgenerational transmission of maternal psychopathology [16, 23], the path models suggest that children with mothers who have experienced symptoms of depression, anxiety, and hostility are more likely to display internalizing and externalizing behaviors. Therefore, examining the presence of different symptoms in mothers rather than relying on a specific psychological complaint can be crucial in detecting early precursors of child problem behaviors and designing effective clinical interventions.

Furthermore, our findings indicated that SES had an indirect effect on child externalizing behaviors via maternal depression, anxiety, and hostility. However, SES had an indirect effect on internalizing behaviors via maternal depression and hostility, but not via anxiety. As in one longitudinal study [96], showing lower SES is associated with maternal anxiety that, in turn, can increase child externalizing problems; in the present study, however, it was found not to increase internalizing behaviors. Our findings suggest that SES could be an important risk factor for those mothers potentially suffering from emotion dysregulation due to the aforementioned symptom characteristics, which could, in turn, escalate child problem behaviors.

\section{Maternal Cognitive Aspect of Mentalization}

Our findings indicate that higher level of maternal mentalization is related to less severe child internalizing and externalizing behaviors. Nonetheless, when we tested the effect of maternal symptoms on child problem behaviors in the separate path models with other maternal factors, mentalization did not predicted child problem behaviors except for the anxiety model. Mentalization predicted only externalizing behaviors, not internalizing ones in the anxiety model. For mothers reporting relatively high anxiety, it may be difficult to pay attention to a child's signaling, mental states, and emotions [15, 35]. As previous research has indicated [97], higher levels of maternal mentalization might work better to decrease the child's externalizing behaviors when maternal anxiety is taken into consideration. Although previous research noted the association between mentalization and child internalizing behaviors [97], our path models did not reveal this relationship. It is possible that negative intentionality and unsupportive emotion socialization contribute more strongly to child internalizing behaviors than mentalization in our sample.

The study revealed that there was no mediating role for mentalization in the links between maternal symptoms and child problem behaviors. Previously, studies have highlighted that negative aspects of parenting might be more critical than positive aspects for the development of childhood psychopathology $[98,99]$. In line with these studies, negative intentionality and unsupportive emotion socialization predicted child problem behaviors more than mentalization in our models and their mediating roles were more pronounced. Therefore, in our study, the mediating role of mentalization in the relationship between maternal symptoms and child behavior problems is less than conclusive.

Nevertheless, we found that maternal mentalization mediated the association between SES and child externalizing problems in the anxiety model. This finding suggests that mentalization plays a possible protective role for socially and economically advantaged mothers with children who exhibit externalizing problems. Thus, maternal mentalization seems to require a more comprehensive evaluation that considers other maternal factors, such as SES, that potentially impact this elaborative processing [100].

\section{The Maternal Cognitive Aspect of Negative Intentionality}

Negative intentionality positively predicted child externalizing problems in all models. Consistent with previous research [51,101], our findings suggest that, regardless of maternal symptoms, when mothers ascribe negative attributions to their children's conduct, they are more likely to promote aggressive behaviors in them. Hence, interventions 
focusing on the period of toddlerhood might consider the possible impact of maternal negative intentionality on children's externalization problem behaviors. Furthermore, maternal negative intentionality was positively related to child internalizing behaviors. However, in the separate models-maternal depression, anxiety, and hostility—negative intentionality predicted child internalizing behaviors only in the hostility model. The lack of a link between maternal negative intentionality and child internalizing problems in the depression and anxiety models might be due to the relevance of maternal depression and anxiety for child internalizing behavior problems. Accordingly, they may explain more variance in the models. Mothers with hostility symptoms may engage in more blame attributions or negative intentionality concerning children's actions, which can result in the development of shame and guilt in children [52, 102], thus potentially contributing to the later development of child internalizing behaviors.

Our findings also showed that negative intentionality acts as a mediator only in the relationship between maternal hostility and internalizing behaviors. Previously, research demonstrated that hostility is strongly associated with ascribing negative outside attributions [103]. There is no study covering early childhood, but a study with adolescents suggested that hostile behaviors, rejection, and neglect can impact adolescent depression and anxiety [104]. Consistent with the research on adolescents, our findings indicate that detecting mothers' hostility can be important in preventing child internalizing behaviors. Furthermore, our findings also revealed that maternal depression, anxiety, and hostility are related to more maternal negative attributions and thoughts about children's acts conduct, which, in turn, predicted child externalizing behaviors. In parallel with previous research [44, 59], our study supports Beck's cognitive model of depression, suggesting that depressed individuals display more negative biases than healthy individuals [105]. Besides, social anxiety, generalized anxiety disorder [106], and hostility [107] are linked to cognitive distortions affecting interpersonal relationships. Thus, the mediational association of negative intentionality supports the model [58], indicating differential relations of maternal symptoms with both types of child problem behaviors. In line with these studies, our findings suggest that different maternal symptoms can potentially act as risk factors for toddlers' externalizing and internalizing behaviors through maternal negative intentionality.

\section{Unsupportive Emotion Socialization}

As hypothesized, unsupportive emotion socialization negatively predicted child internalizing and externalizing behaviors in all maternal symptom models. We demonstrate that, regardless of any maternal symptoms, when experiencing negative emotions, children seem to suffer from mothers' distress, and minimized, and punitive reactions that escalate their problem behaviors even at younger ages. Confirming the results of previous studies [108, 109], we suggest that if children express negative emotions, mothers should avoid unsupportive emotion socialization strategies to prevent the emergence of problem behaviors.

As expected, unsupportive emotion socialization was predicted by maternal depression, anxiety, and hostility and played a mediating role in the links between these three maternal symptoms and child internalizing and externalizing behaviors. In line with previous research $[61,110]$, our findings demonstrate that mothers with any kind of symptom-depression, anxiety, or hostility-can drift away from optimal emotion socialization strategies, which can, in turn, prompt child problem behaviors. Based on the stages of social information processing of physical abuse [62, 111], maternal symptomatology can adversely impact the way mothers implement appropriate responses and effectively monitor the consequences of their actions as they engage with their children.

Furthermore, in all three maternal symptom models, the maternal cognitive aspects of mentalization and negative intentionality predicted unsupportive emotion socialization. Consistent with previous studies [72, 112, 113], our findings suggest that low mentalization and high negative perception about child intentions may be potential risk factors for maternal harsh discipline and punishment. However, unsupportive emotion socialization did not act as a mediator between maternal cognitive aspects and child problem behaviors in any path models. Following established models [30, 58], the present study explored the mediational role of unsupportive emotion socialization but did not provide evidence. Nevertheless, we need to keep in mind that in all models, SES, maternal symptoms, and emotion socialization are consistently significant predictors of child problems. Also, there are two mediation roles of both maternal symptoms and emotion socialization in the link between SES and child problems highlighted in all models. Thus, when the overriding effects of SES, unsupportive emotion socialization, and maternal symptoms are considered, maternal cognitive aspects may not be left with statistical power to explain the variance in child problems through unsupportive emotion socialization.

Finally, unsupportive emotion socialization did mediate the association between SES and child problem behaviors in all maternal symptom models. Consistent with the previous literature $[114,115]$, these findings indicate that low SES is likely to be a risk factor for negative parenting that is linked to child problem behaviors as well. 


\section{Limitations and Future Directions}

The results of the present study are based on cross-sectional maternal self-report data. However, for certain factors such as maternal mentalization, using other methods [34] can capture the mentalization capacity in action [116]. Additionally, multiple reporters like fathers, other caregivers, and significant others, as well as clinical assessments for child problem behaviors, can eliminate the shared method variance issue. Longitudinal designs are necessary to examine the causal relationships and the role of protective and risk factors in child problem behaviors. In the present study, we only focused on maternal symptoms and parenting characteristics, but paternal symptomatology and behaviors can affect children [117]. Therefore, future studies should include coparents. Importantly, other factors need to be examined in a hierarchy, and their possible contribution to interventions and psychotherapy should be addressed. For example, certain personality characteristics (i.e., perfectionism, [118]) and cognitive and emotional engagement of the mothers for rapport building [119] can influence treatment outcomes.

\section{Summary}

The study reveals several important findings. First, child internalizing and externalizing behaviors are affected by different maternal symptoms. We provide evidence for the transgenerational transmission of maternal psychopathology governed by the multifinality principle in toddlerhood. Second, maternal cognitive aspects are essential in both preventing and promoting child problem behaviors. Maternal mentalization can play a protective role vis-à-vis child problem behaviors, and especially so among socioeconomically advantaged mothers concerning child externalizing behaviors. However, maternal negative intentionality can directly increase child externalizing and internalizing behaviors. In addition to its direct effects, negative intentionality mediates the links between all maternal symptoms and child externalizing behaviors as well as between maternal hostility and internalizing behaviors. Thus, the positive aspect of maternal cognition has a relatively limited impact on child problem behaviors compared to negative ones.

Third, unsupportive emotion socialization carries a detrimental role in problem behaviors because it predicts internalizing and externalizing behaviors in all models. Further, it acts as a mediator between SES and child problem behaviors as well as between all maternal symptoms and child problem behaviors. Finally, SES comes out as an important factor since it has a substantial impact on both child problems directly and indirectly via maternal symptoms, cognitive aspects, and unsupportive emotion socialization. Consequently, the present study contributes to our understanding of early maternal indicators of toddler problem behaviors, which can enable clinical prevention programs, guide practitioners, and promote effective policies to eliminate further child psychopathology.

Author Contributions GA: designed, executed, conducted the analysis and wrote the paper. AK: collaborated with the design, analysis and the writing.

Funding This study was funded by The Scientific and Technological Research Council of Turkey (TUBITAK) Career Grant No: 114K813.

\section{Compliance with Ethical Standards}

Conflict of interest Gizem Arikan (Ph.D.) declares that she has received Career Grant (No: 114K813) from The Scientific and Technological Research Council of Turkey (TUBITAK) and has no other conflict of interest. Asiye Kumru (Ph.D.) declares that she has no conflict of interest.

Ethical Approval The current research was approved by the Ozyegin University ethics committee. All procedures in the study involving human participants were in accordance with the ethical standards of the institutional research committee and with the 1964 Helsinki Declaration and its amendments or comparable ethical standards.

Informed Consent Informed consent was obtained from all the participants.

\section{References}

1. Bayer JK, Sanson AV, Hemphill SA (2006) Parent influences on early childhood internalizing difficulties. J App Dev Psychol 27:542-559

2. Wenar C, Kerig P (2000) Developmental psychopathology: from infancy through adolescence. McGraw-Hill, New York

3. Toumbourou JW, Williams I, Letcher P, Sanson A, Smart D (2011) Developmental trajectories of internalising behaviour in the prediction of adolescent depressive symptoms. Aust J Psychol 63:214-223

4. Reef J, Diamantopoulou S, van Meurs V, Verhulst FC, Ende JVD (2011) Developmental trajectories of child to adolescent externalizing behavior and adult DSM-IV disorder: results of a 24-year longitudinal study. Soc Psychiatr Epidemiol 46:1233-1241

5. Achenbach TM, Rescorla L (2000) Manual for the Child Behavior Checklist/11/2-5 and 2001 profile. University of Vermont Department of Child Psychiatry, Burlington

6. Carter AS, Briggs-Gowan MJ, Jones SM, Little TD (2003) The infant-toddler social and emotional assessment (ITSEA): Factor structure, reliability, and validity. J Abnorm Child Psychol $31: 495-514$

7. van Zeijl J, Mesman J, Stolk MN, Alink LRA, van Ijzendoorn MH, Bakermans-Kranenburg M et al (2006) Terrible ones? Assessment of externalizing behaviors in infancy with the Child Behavior Checklist. J Child Psychol Psychiatry 47:801-810

8. Eisenhower AS, Baker BL, Blacher J (2009) Children's delayed development and behavior problems: impact on mothers' perceived physical health across early childhood. Soc Sci Med 68:89-99 
9. Renk K (2011) Mothers' perceptions of young children, parenting, and young children's behavior problems. Child Fam Behav Therapy 33:123-138

10. Visser JH, Ende JVD, Koot HM, Verhulst FC (2000) Predictors of psychopathology in young adults referred to mental health services in childhood or adolescence. Brit J Psychiatry 177:59-65

11. Van Aken C, Junger M, Verhoeven M, van Aken MA, Deković M, Denissen JJA (2007) Parental personality, parenting and toddlers' externalising behaviours. Eur J Pers 21:993-1015

12. Bronfenbrenner U (1989) Ecological systems theory. Ann Child Dev 6:187-249

13. Parritz RH, Troy M (2013) Handbook of child psychopathology, 2nd edn. Wadsworth Cengage Learning, Boston

14. Luoma I, Koivisto AN, Tamminen T (2004) Fathers' and mothers' perceptions of their child and maternal depressive symptoms. Nord J Psychiatry 58:205-211

15. Van den Bergh BRH, Marcoen A (2004) High antenatal maternal anxiety is related to ADHD symptoms externalizing problems, and anxiety in 8- and 9-year-olds. Child Dev 75:1085-1097

16. Teyhan A, Galobardes B, Henderson J (2014) Child allergic symptoms and mental well-being: the role of maternal anxiety and depression. J Pediatr 165:592-599.e5

17. Barker ED, Jaffee SR, Uher R, Maughan B (2011) The contribution of prenatal and postnatal maternal anxiety and depression to child maladjustment. Depress Anxiety 28:696-702

18. Betts KS, Williams GM, Najman JM, Alati R (2014) Maternal depressive, anxious, and stress symptoms during pregnancy predict internalizing problems in adolescence. Depress Anxiety 31:9-18

19. Beck AT, Clark DA (1998) Anxiety and depression: An information processing perspective. Anxiety Res 1:23-36

20. Sharp C, Fonagy P, Goodyer IM (2006) Imagining your child's mind: Psychosocial adjustment and mothers' ability to predict their children's attributional response styles. Br J Dev Psychol 24:197-214

21. Suveg C, Shaffer A, Morelen D, Thomassin K (2011) Links between maternal and child psychopathology symptoms: mediation through child emotion regulation and moderation through maternal behavior. Child Psychiatry Hum Dev 42:507

22. Curran T, Samp JA, Janovec A (2017) Transgenerational patterns of communication orientations and depression among mothers and adult children. Com Stud 6:278-295

23. Maciejewski DF, Hillegers M, Penninx B (2018) Offspring of parents with mood disorders: time for more transgenerational research, screening and preventive intervention for this high-risk population. Curr Opin Psychiatry 31:349-357

24. Goodman SH, Rouse MH, Connell AM, Broth MR, Hall CM, Heyward D (2011) Maternal depression and child psychopathology: a meta-analytic review. Clin Child Fam Psychol Rev $14: 1-27$

25. Weisman MM, Piowsky DJ, Wickermaratne PJ (2006) Remissions in maternal depression and child psychopathology. JAMA 295:1389-1398

26. Weissman MM, Warner V, Wickramaratne P, Moreau D, Olfson M (1997) Offspring of depressed parents: 10 years later. Arch Gen Psychiatry 54:932-940

27. Kaufman EA, Puzia ME, Mead HK, Crowell SE, McEachern A, Beauchaine TP (2017) Children's emotion regulation difficulties mediate the association between maternal borderline and antisocial symptoms and youth behavior problems over 1 year. J Pers Disord 31:170-192

28. American Psychiatric Association (2013) Diagnostic and statistical manual of mental disorders (5th ed.; DSM-5). American Psychiatric Association, Washington

29. Yildirim ED, Roopnarine JL (2015) The mediating role of maternal warmth in the associations between harsh parental practices and externalizing and internalizing behaviors in Hispanic American, African American, and European American families. Cultur Divers Ethnic Minor Psychol 21:430-439

30. Talge NM, Neal C, Glover V (2007) Antenatal maternal stress and long-term effects on child neurodevelopment: how and why? J Child Psychol Psychiatry 48:245-261

31. Hosman CM, van Doesum KT, van Santvoort F (2009) Prevention of emotional problems and psychiatric risks in children of parents with a mental illness in the Netherlands: I. The scientific basis to a comprehensive approach. AeJAMH 8:250-263

32. Kim-Cohen J, Caspi A, Rutter M, Tomás MP, Moffitt TE (2006) The caregiving environments provided to children by depressed mothers with or without an antisocial history. Am J Psychiatry 163:1009-1018

33. Fonagy P, Target M (1998) Mentalization and the changing aims of child psychoanalysis. Psychoanal Dialogues 8:87-114

34. Ensink K, Mayes LC (2010) The development of mentalization in children from a theory of mind perspective. Psychoanal Inq 30:201-337

35. Slade A, Grienenberger J, Bernbach E, Levy D, Locker A (2005) Maternal reflective functioning, attachment, and the transmission gap: a preliminary study. Attach Hum Dev 7:283-298

36. Sharp C, Fonagy P (2008) The parent's capacity to treat the child as a psychological agent: constructs, measures and implications for developmental psychopathology. Soc Dev 17:737-754

37. Meins E (1997) Security of attachment and the social development of cognition. Psychology Press, Hove

38. Meins E, Fernyhough C (1999) Linguistic acquisitional style and mentalising development: the role of maternal mind-mindedness. Cogn Dev 14:363-380

39. Meins E, Fernyhough C, Russell J, Clark-Carter D (1998) Security of attachment as a predictor of symbolic and mentalising abilities: a longitudinal study social development. Soc Dev $7: 1-24$

40. Kiel EJ, Viana AG, Tull MT, Gratz KL (2017) Emotion socialization strategies of mothers with borderline personality disorder symptoms: the role of maternal emotion regulation and interactions with infant temperament. J Pers Disord 31:399-416

41. Smaling HJ, Huijbregts SC, Suurland J, van der Heijden KB, Mesman J, van Goozen SH et al (2016) Prenatal reflective functioning and accumulated risk as predictors of maternal interactive behavior during free play, the still-face paradigm, and two teaching tasks. Infancy 21:766-784

42. Smaling HJ, Huijbregts SC, van der Heijden KB, van Goozen SH, Swaab H (2017) Maternal reflective functioning as a multidimensional construct: differential associations with children's temperament and externalizing behavior. Infant Behav Dev 44:263-274

43. Klein M (1975) Envy and gratitude and other works 1946-1963. Delacorte Press, New York

44. Fonagy P, Target $M(2000)$ The place of psychodynamic theory in developmental psychopathology. Dev Psychopathol 12:407-425

45. Feldman R, Reznick JS (1996) Maternal perception of infant intentionality at 4 and 8 months. Infant Behav Dev 19:483-496

46. Burchinal M, Skinner D, Reznick JS (2010) European American and African American mothers' beliefs about parenting and disciplining infants: a mixed-method analysis. Parent Sci Pract 10:79-96

47. Bandura A (1973) Aggression: a social learning analysis. Prentice-Hall, Oxford

48. Nix RL, Pinderhughes EE, Dodge KA, Bates JE, Pettit GS, McFadyen-Ketchum SA (1999) The relation between mothers' hostile attribution tendencies and children's externalizing behavior problems: the mediating role of mothers' harsh discipline practices. Child Dev 70:896-909 
49. Park JL, Johnston C, Colalillo S, Williamson D (2018) Parents' attributions for negative and positive child behavior in relation to parenting and child problems. J Clin Child Adolesc Psychol 47:63-75

50. Wilson C, Gardner F, Burton J, Leung S (2006) Maternal attributions and young children's conduct problems: a longitudinal study. Infant Child Dev 15:109-121

51. Snyder J, Cramer A, Afrank J, Patterson GR (2005) The contributions of ineffective discipline and parental hostile attributions of child misbehavior to the development of conduct problems at home and school. Dev Psychol 41:30-41

52. Arikan G, Kumru A, Korkut B, Ilhan AO (2019) Examining Toddlers' problem behaviors: the role of SES, parenting stress, perceived support and negative intentionality. J Child Fam Stud 28:3467-3478

53. Erikson EH (1968) Identity: youth and crisis. Norton, New York

54. Eisenberg N, Fabes RA, Shepard SA, Guthrie IK, Murphy BC, Reiser M (1999) Parental reactions to children's negative emotions: longitudinal relations to quality of children's social functioning. Child Dev 70:513-534

55. Bolton C, Calam R, Barrowclough C, Peters S, Roberts J, Wearden A et al (2003) Expressed emotion, attributions and depression in mothers of children with problem behaviour. $\mathbf{J}$ Child Psychol Psychiatry 44:242-254

56. Root AE, Byrne R, Watson SM (2014) The regulation of fear: the contribution of inhibition and emotion socialisation. Early Child Dev Care 185:647-657

57. Root AK, Denham SA (2010) The role of gender in the socialization of emotion: key concepts and critical issues. New Dir Child Adolesc Dev 2010:1-9

58. Gottman JM, Katz LF, Hooven C (1996) Parental meta-emotion philosophy and the emotional life of families: theoretical models and preliminary data. J Fam Psychol 10:243-268

59. Goodman SH, Gotlib IH (1999) Risk for psychopathology in the children of depressed mothers: a developmental model for understanding mechanisms of transmission. Psychol Rev 106:458-490

60. Schechter DS, Moser DA, Reliford A, McCaw JE, Coates SW, Turner JB et al (2015) Negative and distorted attributions towards child, self, and primary attachment figure among posttraumatically stressed mothers: what changes with clinician assisted videofeedback exposure sessions (CAVES). Child Psychiatry Hum Dev 46:10-20

61. Elgar FJ, Mills RS, McGrath PJ, Waschbusch DA, Brownridge DA (2007) Maternal and paternal depressive symptoms and child maladjustment: the mediating role of parental behavior. J Abnorm Child Psychol 35:943-955

62. van Der Bruggen CO, Stams GJJ, Bögels SM (2008) Research review: The relation between child and parent anxiety and parental control: a meta-analytic review. J Child Psychol Psychiatry 49:1257-1269

63. Creswell C, Apetroaia A, Murray L, Cooper P (2013) Cognitive, affective, and behavioral characteristics of mothers with anxiety disorders in the context of child anxiety disorder. J Abnorm Psychol 122:26-38

64. Suveg C, Zeman J, Flannery-Schroeder E, Cassano M (2005) Emotion socialization in families of children with an anxiety disorder. J Abnorm Child Psychol 33:145-155

65. Banks T, Ninowski JE, Mash EJ, Semple DL (2008) Parenting behavior and cognitions in a community sample of mothers with and without symptoms of attention-deficit/hyperactivity disorder. J Child Fam Stud 17:28-43

66. Teti DM, Gelfand DM (1997) Maternal cognitions as mediators of child outcomes in the context of postpartum depression. In: Murray L, Cooper PJ (eds) Postpartum depression and child development. Guilford Press, London, pp 136-164
67. Fabes R, Poulin RE, Eisenberg N, Madden-Derdich DA (2002) The Coping with Children's Negative Emotions Scale (CCNES): Psychometric properties and relations with children's emotional competence. Marriage Fam Rev 34:285-310

68. Morelen D, Shaffer A, Suveg C (2016) Maternal emotion regulation: Links to emotion parenting and child emotion regulation. J Fam Issues 37:1891-1916

69. Eisenberg N, Spinrad TL, Cumberland A (1998) The socialization of emotion: Reply to commentaries. Psychol Inq 9:317-333

70. Dix T, Gershoff ET, Meunier LN, Miller PC (2004) The affective structure of supportive parenting: depressive symptoms, immediate emotions, and child-oriented motivations. Dev Psychol 40:1212-1227

71. Sanders W, Zeman J, Poon J, Miller R (2015) Child regulation of negative emotions and depressive symptoms: the moderating role of parental emotion socialization. J Child Fam Stud 24:402-415

72. Möller C, Odersjö C, Pilesjö F, Terpening K, Österberg M, Holmqvist R (2017) Reflective functioning, limit setting, and emotional availability in Mother-Child dyads. Parent Sci Pract $17: 225-241$

73. Oppenheim D, Goldsmith D, Koren-Karie N (2004) Maternal insightfulness and preschoolers' emotion and behavior problems: Reciprocal influences in a therapeutic preschool program. Infant Ment Health J 25:352-367

74. Turkish Statistical Institute (2016) Report. Retrieved from: www. tuik.gov.tr/UstMenu.do?metod=temelist Accessed May 2019

75. Derogatis LR (1992) The Brief Symptom Inventory-BSI administration, scoring and procedures manual-II. Clinical Pscyhometric Research Inc, Baltimore

76. Sahin NH, Durak A (1995) Üniversite Öğrencileri İçin Bir Stresle Başa Çıkma Tarzı Ölçeği. Türk Psikoloji Dergisi 10:56-73

77. Luyten P, Mayes LC, Sadler L, Fonagy P, Nicholls S, Crowley M et al (2009) The Parental Reflective Functioning Questionnaire-1. Unpublished manuscript, University of Leuven, Leuven, Belgium

78. Karabulut D, Ilhan A, Kumru A, Arikan G (2016) Erken Çocukluk Döneminde Ebeveyn İçsel Düşünme İşlevselliği Ölçeği'nin Türk Örnekleminde Görülen Sosyometrik Yapısı. Poster presented at the 52nd National Psychiatry Congress, Antalya, Turkey

79. Reznick JS (2008) Inferring infant intentionality. VDM Dr. Müller, Berlin

80. Karabulut D, İlhan A, Kumru A, Arıkan G (2016) Turkish psychometric properties of Infant Intentionality Questionnaire during early childhood period. Poster presented at the 52nd National Psychiatry Congress, Antalya, Turkey

81. Arikan G (2016) Improving Mother-child Attachment Relationship with Circle of Security Parenting Training Program. The Scientific and Technological Research Council of Turkey (TUBITAK), Turkish National Young Researchers Career Development Program (3501-CAREER), Project no: 114K813, 1st Report

82. Achenbach TM (1991) Manual for the Child Behavior Checklist 04-18 and 1991 Profile. University of Vermont, Department of Psychiatry, Burlington, Burlington

83. Erol N, Şimşek Z (1997) Türkiye Ruh Sağlı̆̆ı Profili: Çocuk ve gençlerde yeterlik alanları ile sorun davranışların dağılımı. In: Erol N, Kılıç C, Ulusoy M, Keçeci M, Şimşek Z (eds) Türkiye Ruh Sağlığı Profili: Ön Rapor. Aydoğdu Ofset, Ankara, pp 12-33

84. IBM Corp. Released 2012. IBM SPSS Statistics for Windows, Version 20.0. Armonk, IBM Corp. NY

85. Muthén LK, Muthén BO (2017) Mplus: statistical analysis with latent variables: user's guide (version 8). Authors, Clos Angles

86. Tabachnick BG, Fidell LS (2001) Using multivariate statistics, 4th edn. Allyn \& Bacon, Boston, MA

87. Browne MW, Cudeck R (1993) Alternative ways of assessing model fit. In: Bollen KA, Long JS (eds) Testing structural equation models. Sage, Newbury Park, CA, pp 136-162 
88. Steiger JH (1990) Structural model evaluation and modification: an interval estimation approach. Multivariate Behav Res 25:173-180

89. Hu L, Bentler P (1995) Evaluating model fit. In: Hoyle RH (ed) Structural equation modeling. Concepts, issues, and applications. Sage, London, pp 76-99

90. Fan X, Thompson B, Wang L (1999) Effects of sample size, estimation methods, and model specification on structural equation modeling fit indexes. Struct Equ Modeling 6:56-83

91. Kline RB (2005) Principles and practice of structural equation modeling, 2nd edn. The Guilford Press, New York

92. Pollack MH (2005) Comorbid anxiety and depression. J Clin Psychiatry 66:22-29

93. Johansson R, Carlbring P, Heedman A, Paxling B, Andersson G (2013) Depression, anxiety and their comorbidity in the Swedish general population: point prevalence and the effect on healthrelated quality of life. PeerJ 1:e98

94. Stordal E, Morken G, Mykletun A, Neckelmann D, Dahl AA (2008) Monthly variation in prevalence rates of comorbid depression and anxiety in the general population at $63-65^{\circ}$ North: the HUNT study. J Affect Disord 106:273-278

95. Adèr HJ, Mellenbergh GJ, Hand DJ (2008) Advising on research methods: a consultant's companion. Johannes van Kessel Publishing, Huizen

96. Allen JG, Fonagy P (eds) (2006) The handbook of mentalizationbased treatment. Wiley, Hoboken

97. Ensink K, Bégin M, Normandin L, Fonagy P (2017) Parental reflective functioning as a moderator of child internalizing difficulties in the context of child sexual abuse. Psychiatry Res 257:361-366

98. Lovejoy MC, Graczyk PA, O’Hare E, Neuman G (2000) Maternal depression and parenting behavior. Clin Psychol Rev 20:561-592

99. Sellers R, Harold GT, Elam K, Rhoades KA, Potter R, Mars $\mathrm{B}$ et al (2014) Maternal depression and co-occurring antisocial behaviour: testing maternal hostility and warmth as mediators of risk for offspring psychopathology. J Child Psychol Psychiatry 55:112-120

100. Muscatell KA, Morelli SA, Falk EB, Way BM, Pfeifer JH, Galinsky AD et al (2012) Social status modulates neural activity in the mentalizing network. Neuroimage 60:1771-1777

101. Baden AD, Howe GW (1992) Mothers' attributions and expectancies regarding their conduct-disordered children. J Abnorm Child Psychol 20:467-485

102. Alessandri SM, Lewis M (1996) Differences in pride and shame in maltreated and nonmaltreated preschoolers. Child Dev 67:1857-1869

103. Gudjonsson GH, Singh KK (1989) The revised Gudjonsson blame attribution inventory. Pers Individ Dif 10:67-70

104. Epkins CC, Harper SL (2016) Mothers' and fathers' parental warmth, hostility/rejection/neglect, and behavioral control: Specific and unique relations with parents' depression versus anxiety symptoms. Parent Sci Pract 16:125-145

105. Beck AT, Bredemeier K (2016) A unified model of depression: integrating clinical, cognitive, biological, and evolutionary perspectives. Clin Psychol Sci 4:596-619

106. Newman MG, Jacobson NC, Zainal NH, Shin KE, Szkodny LE, Sliwinski MJ (2019) The effects of worry in daily life: an ecological momentary assessment study supporting the tenets of the contrast avoidance model. Clin Psychol Sci 7:794-810

107. Asberg K (2013) Hostility/anger as a mediator between college students' emotion regulation abilities and symptoms of depression, social anxiety, and generalized anxiety. J Psychol 147:469-490

108. Johnson AM, Hawes DJ, Eisenberg N, Kohlhoff J, Dudeney J (2017) Emotion socialization and child conduct problems: a comprehensive review and meta-analysis. Clin Psychol Rev 54:65-80

109. van der Pol LD, Groeneveld MG, Endendijk JJ, van Berkel SR, Hallers-Haalboom ET, Bakermans-Kranenburg MJ et al (2016) Associations between fathers' and mothers' psychopathology symptoms, parental emotion socialization, and preschoolers' social-emotional development. J Child Fam Stud 25:3367-3380

110. Milner JS (1993) Social information processing and physical child abuse. Clin Psychol Rev 13:275-294

111. Milner JS (2000) Social information processing and child physical abuse: theory and research. In: Hansen DJ (ed) Nebraska symposium on motivation, Vol. 46, 1998: motivation and child maltreatment. University of Nebraska Press, Lincoln, pp 39-84

112. Martini TS, Root CA, Jenkins JM (2004) Low and middle income mothers' regulation of negative emotion: effects of children's temperament and situational emotional responses. Soc Dev $13: 515-530$

113. Vostanis P, Graves A, Meltzer H, Goodman R, Jenkins R, Brugha $\mathrm{T}$ (2006) Relationship between parental psychopathology, parenting strategies and child mental health. Soc Psychiatry Epidemiol 41:509-514

114. Barroso NE, Mendez L, Graziano PA, Bagner DM (2018) Parenting stress through the lens of different clinical groups: a systematic review \& meta-analysis. J Abnorm Child Psychol 46:449-461

115. Graves SL Jr, Blake J, Kim ES (2012) Differences in parent and teacher ratings of preschool problem behavior in a national sample: the significance of gender and SES. J Early Interv 34:151-165

116. Camoirano A (2017) Mentalizing makes parenting work: a review about parental reflective functioning and clinical interventions to improve it. Front Psychol 8:14

117. Murdock KW, Pittman LD, Fagundes CP (2018) Maternal and paternal predictors of child depressive symptoms: an actor-partner interdependence framework. J Child Fam Stud 27:559-568

118. Vandenberk T, Lanssens D, Storms V, Thijs IM, Bamelis L, Grieten L et al (2019) Relationship between adherence to remote monitoring and patient characteristics: observational study in women with pregnancy-induced hypertension. JMIR Mhealth Uhealth 7:e12574

119. Chatoor I, Kurpnick J (2001) The role of non-specific factors in treatment outcome of psychotherapy studies. Eur Child Adolesc Psychiatry 10:I/19-I/25

Publisher's Note Springer Nature remains neutral with regard to jurisdictional claims in published maps and institutional affiliations. 